DOI https://doi.org/10.15589/znp2019.2(476).3

УДК 621.3.076.7

\title{
IDENTIFICATION METHOD OF ELECTRICAL PARAMETERS OF THE INTERIOR PERMANENT MAGNETS SYNCHRONOUS MOTORS
}

\section{МЕТОД ВИЗНАЧЕННЯ ЕЛЕКТРИЧНИХ ПАРАМЕТРІВ ЯВНОПОЛЮСНИХ СИНХРОННИХ ДВИГУНІВ}

\author{
Serhii M. Peresada \\ sergei.peresada@gmail.com \\ ORCID: 0000-0001-8948-722X \\ Yevhen O. Nikonenko \\ evgeniy.nykonenko@gmail.com \\ ORCID: 0000-0003-2379-5566 \\ Viktor S. Reshetnyk \\ reshetnik93@gmail.com \\ ORCID: 0000-0002-8428-0446
}

С. М. Пересада,

докт. техн. наук, професор

\section{Є. О. Ніконенко,}

аспірант

\section{В. С. Решетник,}

аспірант

\section{National Technical University of Ukraine "Igor Sikorsky Kyiv Polytechnic Institute”, Kyiv \\ Наиіональний технічний університет Украйни «Київський політехнічний інститут імені Ігоря Сікорського», м. Київ}

\begin{abstract}
The paper is devoted to research and development of novel identification method of static and incremental inductances, as well as permanent magnets flux of interior permanent magnets synchronous motors.

The relevance of the identification methods design for the synchronous motors electrical parameters during a selfcommissioning procedure is substantiated.

The proposed method is based on the flux linkages estimation in a current-controlled closed-loop system with robustness properties with respect to inverter nonlinearities.

The experimental installation with an interior permanent magnets synchronous motorwas developed, manufactured and configured for the verification of the proposed method. A set of programs was developed for the method testing as well. The installation can be used to investigate a wide range of control algorithms for electromechanical systems with interior permanent magnets synchronous motors.

The experimental study demonstrates that the presented method guarantees the identification of static and incremental inductances, as well as permanent magnets flux of the interior permanent magnets synchronous motor. The identification algorithm has a typical structure of the modern vector-controlled electrical drives.It can be used to improve the dynamic performance and efficiency of vector-controlled interior permanent magnets synchronous motors in torque, speed or positions control modes. Additionally, the estimated fluxes provide the information about saturation of the synchronous motor magnetic system.

From the results of the experimental study, it follows that the influence of the cross-coupling is insignificant for the investigated interior permanent magnets synchronous motor. It is shown that the saturation of the magnetic system is negligible for the working range of the stator currentsas well.

The validity of the conclusions and recommendations are confirmed by the coincidence of the simulation study results with the experimental data.
\end{abstract}

Key words: interior permanent magnets synchronous motor; flux linkage estimation; static and incremental inductances.

Анотація. Робота присвячена питанням розробки та дослідження нового методу визначення статичних та інкрементальних індуктивностей, а також значення магнітного потоку постійних магнітів явнополюсних синхронних двигунів із постійними магнітами при самоналаштуванні.

Обгрунтовано актуальність розробки методів ідентифікації електричних параметрів явнополюсних синхронних двигунів при самоналаштуванні синхронних електроприводів.

Розроблений метод ідентифікації електричних параметрів явнополюсних синхронних двигунів базується на визначенні оцінених значень потокозчеплень двигуна в замкненій системі регулювання струмів із властивостями робастності до неідеальностей інвертора.

Для верифікації методу розроблено, виготовлено та налаштовано експериментальну установку з явнополюсним синхронним двигуном із постійними магнітами, а також комплекс програм для дослідження методу ідентифікації індуктивностей і магнітного потоку постійних магнітів двигуна. Установка може застосовуватися для дослідження широкого спектру алгоритмів керування електромеханічними системами 3 явнополюсними синхронними двигунами з постійними магнітами. 


\section{ЕЛЕКТРОЕНЕРГЕТИКА, ЕЛЕКТРОТЕХНIКА ТА ЕЛЕКТРОМЕХАНІКА №2 2019}

Проведене експериментальне дослідження показує, що представлений метод забезпечує визначення статичних та інкрементальних індуктивностей, а також значення магнітного потоку постійних магнітів в умовах самоналаштування явнополюсного синхронного двигуна. Алгоритм ідентифікації має типову структуру сучасних векторно-керованих електроприводів. Він може застосовуватися для підвищення динамічних показників у режимі керування моментом, швидкістю або положенням. Додатково оцінені значення потокозчеплення дають інформацію про насичення магнітної системи синхронного двигуна.

3 результатів експериментального дослідження випливає, що в досліджуваному явнополюсному синхронному двигуні вплив суміжного струму на потокозчеплення є несуттєвим. Також визначено, що насичення магнітної системи є незначним для робочого діапазону зміни струмів статора.

Достовірність та обгрунтованість висновків і рекомендацій підтверджується збігом результатів математичного моделювання з експериментальними даними.

Ключові слова: явнополюсний синхронний двигун з постійними магнітами; оцінювання потокозчеплення; статичні та інкрементальні індуктивності.

\section{ПОСТАНОВКА ЗАДАЧІ}

Явнополюсні синхронні двигуни з постійними магнітами (англ. Interior permanent magnet synchronous motor, IPMSM) є простішими за конструкцією та відповідно дешевшими за неявнополюсні синхронні двигуни [1-4]. Реалізація алгоритмів векторного керування потребує точної інформації про параметри IPMSM [5; 6]. На точність ідентифікації параметрів IPMSM можуть суттєво впливати неідеальності інвертора, основними $з$ яких $\epsilon$ : «мертвий час» інвертора впливає на відпрацювання напруги в зоні малих струмів; еквівалентний активний опір змінюється залежно від режиму роботи інвертора. Також насичення магнітного кола IPMSM впливає на оцінку індуктивностей. Отже, актуальною є розробка методу визначення індуктивностей IPMSM, на точність якого не впливатимуть неідеальності інвертора.

\section{АНАЛІЗ ОСТАННІХ ДОСЛІДЖЕНЬ І ПУБЛІКАЦІЙ}

Методи ідентифікації параметрів поділяються на два класи: онлайн-ідентифікація та офлайн-ідентифікація або процедура самоідентифікації (англ. self-commissioning). Методи онлайн-ідентифікації переважно базуються на використанні адаптивного керування в робочих режимах двигуна [4]. У [7] для ідентифікації індуктивностей застосовано нейронну мережу, а у [8] до двигуна подаються високочастотні прямокутні імпульси струму для оцінки параметрів. Методи офлайн-ідентифікації використовуються в режимі ініціалізації IPMSM і вимагають спеціальних умов тесту. В [9] індуктивності визначаються за виглядом перехідної характеристики струму при ступінчастій зміні напруги статора. Цей підхід вимагає спеціального підключення обмоток статора та нерухомого ротора. У [10] індуктивності обчислюються на основі розрахунку імпедансу статорних обмоток та оцінки втрат у сталі машини з прикладанням високочастотного струмового сигналу. В $[11 ; 12]$ для ідентифікації індуктивностей застосовано алгоритм найменших квадратів в умовах дії прямокутних імпульсів напруги статора. Недоліками методів [9-12] є залежність від неідеальностей інвертора, адже двигун працює в діапазоні «малих» струмів і напруг. Також в $[11 ; 12]$ використовується розімкнене інтегрування струмів, що впливає на точність оцінки параметрів.

\section{МЕТА ДОСЛІДЖЕННЯ}

Метою роботи $є$ розробка методу експериментального визначення статичних та інкрементальних індуктивностей, а також магнітного потоку постійних магнітів IPMSM, на точність результатів якого не впливають неідеальності інвертора і зміни еквівалентного активного опору статора.

\section{ОСНОВНИЙ МАТЕРІАЛ}

За умови, що взаємні індуктивності статора відсутні, після перетворень до синхронної системи координат ротора (d-q) динаміка струмів IPMSM описується такими рівняннями [1]:

$$
\begin{aligned}
& \dot{i}_{d}=-\frac{R}{L_{d}\left(i_{d}\right)} i_{d}+\frac{\Psi_{q}\left(i_{q}\right)}{L_{d}\left(i_{d}\right)} \omega p_{n}+\frac{1}{L_{d}\left(i_{d}\right)} u_{d}, \\
& \dot{i}_{q}=-\frac{R}{L_{q}\left(i_{q}\right)} i_{q}-\frac{\Psi_{d}\left(i_{d}\right)}{L_{q}\left(i_{q}\right)} \omega p_{n}+\frac{1}{L_{q}\left(i_{q}\right)} u_{q},
\end{aligned}
$$

де $\omega$ - кутова швидкість; $u_{d}, u_{q}$ - статорні напруги; $i_{d}, i_{q}$-статорні струми, $R$ - еквівалентний активний опір статорних обмоток; $\Psi_{d}=L_{d}\left(i_{d}\right) i_{d}+L_{m d} i_{f}$, $\Psi_{q}=L_{q}\left(i_{q}\right) i_{q}$ - потокозчеплення за вісями $\mathrm{d}$ та q; $L_{d}\left(i_{d}\right), \quad L_{q}\left(i_{q}\right)$ - індуктивності статора; $L_{m d} i_{f}=$ const - магнітний потік постійних магнітів; $p_{n}$ - кількість пар полюсів.

Відмітимо, що в присутні чотири параметри, які в загальному випадку є невідомими: активний опір $R$, індуктивності $L_{d}\left(i_{d}\right), L_{q}\left(i_{q}\right)$ та магнітний потік постійних магнітів $L_{m d} i_{f}$.

Метод розрахунку індуктивностей $L_{d}\left(i_{d}\right)$, $L_{q}\left(i_{q}\right) i$ магнітного потоку $L_{m d} i_{f}$ полягає в отриманні залежностей потокозчеплення від струму $\Psi_{d}\left(i_{d}\right)$, $i_{q}=0$ та $\Psi_{q}\left(i_{q}\right), i_{d}=0$ за умови: а) швидкість ротора стабілізується зовнішнім рушієм; б) відповідні струми $i_{d}$ та $i_{q}$ змінюються повільно за лінійним законом, так, що динамікою струмів в можна знехтувати.

Для відпрацювання струмів застосовано ПІ-регулятори струму у вигляді 


$$
\begin{array}{ll}
u_{d}=-k_{i} \tilde{i}_{d}-x_{d}, & u_{q}=-k_{i} \tilde{i}_{q}-x_{q}, \\
\dot{\mathrm{x}}_{d}=k_{i i} \tilde{i}_{d}, & \dot{\mathrm{x}}_{q}=k_{i i} \tilde{i}_{q},
\end{array}
$$

де $\tilde{i}_{q}=i_{q}-i_{q}^{*}, \tilde{i}_{d}=i_{d}-i_{d}^{*}-$ похибки регулювання струмів, $i_{q}^{*}, i_{d}^{*}$ - задані значення струмів, $x_{d}, x_{q}-$ інтегральні складники, $k_{i}>0, k_{i i}>0$ - коефіцієнти пропорційної та інтегральної складових частин регуляторів.

Регулятори забезпечують асимптотичність регулювання струмів, тобто $\lim \left(\tilde{i}_{d}, \tilde{i}_{q}\right)=0$ за умови, якщо струм змінюється від $i_{\max }$ до $i_{\min }$ за достатньо великий проміжок часу, що дозволяє розглядати тест як роботу в усталеному режимі $3 i_{d}=0, i_{q}=0$.

Перевагою такого методу є те, що при нульовому суміжному струмі виключається вплив зміни активного опору та нелінійностей інвертора. Умови тесту передбачають роботу в статичному режимі, тому 3 отриманих характеристик потокозчеплень можна визначити насичення магнітної системи, розрахувати індуктивності та магнітний потік постійних магнітів.

Визначення потокозчеплень. В усталеному режимі за умови $i_{d}=0, \dot{i}_{d}=0, \tilde{i}_{d}=03$ залежність потокозчеплення за віссю q дорівнює

$$
\Psi_{q}\left(i_{q}\right)=-\frac{u_{d}}{\omega p_{n}} .
$$

Аналогічно для $i_{q}=0, \dot{i}_{q}=0, \tilde{i}_{q}=0$ потокозчеплення за віссю $\mathrm{d}$ визначається як

$$
\Psi_{d}\left(i_{d}\right)=\frac{u_{q}}{\omega p_{n}} .
$$

За умов $i_{d}=0, i_{q}=0, \omega=$ const 3 рівняння визначається магнітний потік постійних магнітів $L_{m d} i_{f}$ за такою формулою:

$$
L_{m d} i_{f}=\Psi_{d}\left(i_{d}=0\right) .
$$

Після отримання характеристик , для подальшого аналізу вони апроксимуються. Для цього застосовується «Curve Fitting Toolbox» у програмному середовищі MatLab.

Статичні індуктивності $L_{d}, L_{q}$, а також інкрементальні індуктивності $L_{d e}, L_{q e}$ У разі насичення магнітної системи розраховуються за формулами:

$$
\begin{gathered}
L_{d}\left(i_{d}\right)=\frac{\Psi_{d}\left(i_{d}\right)}{i_{d}}, L_{q}\left(i_{q}\right)=\frac{\Psi_{q}\left(i_{q}\right)}{i_{q}}, \\
L_{d e}\left(i_{d}\right)=\frac{\Delta \Psi_{d}}{\Delta i_{d}}, L_{q e}\left(i_{q}\right)=\frac{\Delta \Psi_{q}}{\Delta i_{q}} .
\end{gathered}
$$

Результати експерименту. Для експериментального тестування розроблено, виготовлено та налаштовано експериментальну установку 3 IPMSM потужністю 3 кВт, параметри якого наведено в Додатку.
До складу експериментальної установки, функціональну схему якої показано на рис. 1, входять такі блоки:

- $\quad$ силовий перетворювач потужністю 3 кВт;

- $\quad$ IPMSM потужністю 3 кВт (M1) та асинхронний двигун потужністю 2.2 кВт (М2);

- керуючий контролер на базі 32-розрядного цифрового сигнального процесора TMS320F28335 3 плаваючою комою, в якому програмно реалізуються алгоритми керування IPMSM;

- два фотоімпульсні датчики швидкості (енкодери) з розподільчою здатністю 4096 імп/об;

- пульт керування;

- ПК для програмування контролеру та візуалізації перехідних процесів;

- серійний векторно-керований електропривод для керування асинхронним двигуном М2.

Для визначення положення осі магнітного потоку до однієї обмотки статора IPMSM було подано постійну напругу, внаслідок чого ротор машини був зорієнтований уздовж дії струму. Таке положення відповідає нульовому куту повороту системи координат (d-q) відносно (a-b). Надалі це положення зберігається в пам'яті контролера.

Тестування проведено для постійної швидкості $\omega=157$ рад/с, яка відповідає частоті живлення 50 Гц. Струми $i_{d}$ та $i_{q}$ змінювалися від $i_{\max }=7.5$ А до $i_{\min }=-7.5$ А (значення близькі до номінальних) лінійно від часу, приблизно за 60 с. Прийняті значення коефіцієнтів регуляторів струму $k_{i}=30, k_{i i}=1250$ забезпечують достатню швидкодію контурів регулювання струму для розгляду процесів регулювання струмів як квазіусталених.

Експериментально отримані залежності $\Psi_{d}\left(i_{d}\right)$ та $\Psi_{q}\left(i_{q}\right)$ представлено суцільними лініями чорного кольору на Рис. 2a) та Рис. 2б), тоді як апроксимовані залежності показано штрихованими лініями червоного кольору. Експериментальні дані попередньо відфільтровано без втрати характеру їх зміни. 3 графіків на Рис. 2б) видно, що при нульовому $i_{q}=0$ потокозчеплення $\Psi_{q}\left(i_{q}=0\right) \neq 0$, що потребує додаткового дослідження. Залежність $\Psi_{d}\left(i_{d}\right)$ апроксимована тільки в діапазоні від'ємних значень струму, оскільки цей діапазон відповідає робочому режиму IPMSM.

Вигляд залежностей $\Psi_{d}\left(i_{d}\right)$ і $\Psi_{q}\left(i_{q}\right)$ свідчить, що індуктивність $L_{d}\left(i_{d}\right)$ зменшується зі збільшенням струму $i_{d}>0$ внаслідок насичення магнітної системи, що корелюється 3 даними [9], [13]. Для $i_{d}<0$ у розглянутому діапазоні струмів насичення $\epsilon$ незначним. Індуктивність $L_{q}\left(i_{q}\right)$ також дещо зменшується в зоні номінальних значень струму $i_{q}$, але 3 достатньою для практики точністю може вважатися постійною. Отже, функції потокозчеплень допускають таку лінійну апроксимацію:

$$
\Psi_{d}\left(i_{d}\right)=k_{1} i_{d}+k_{2},
$$




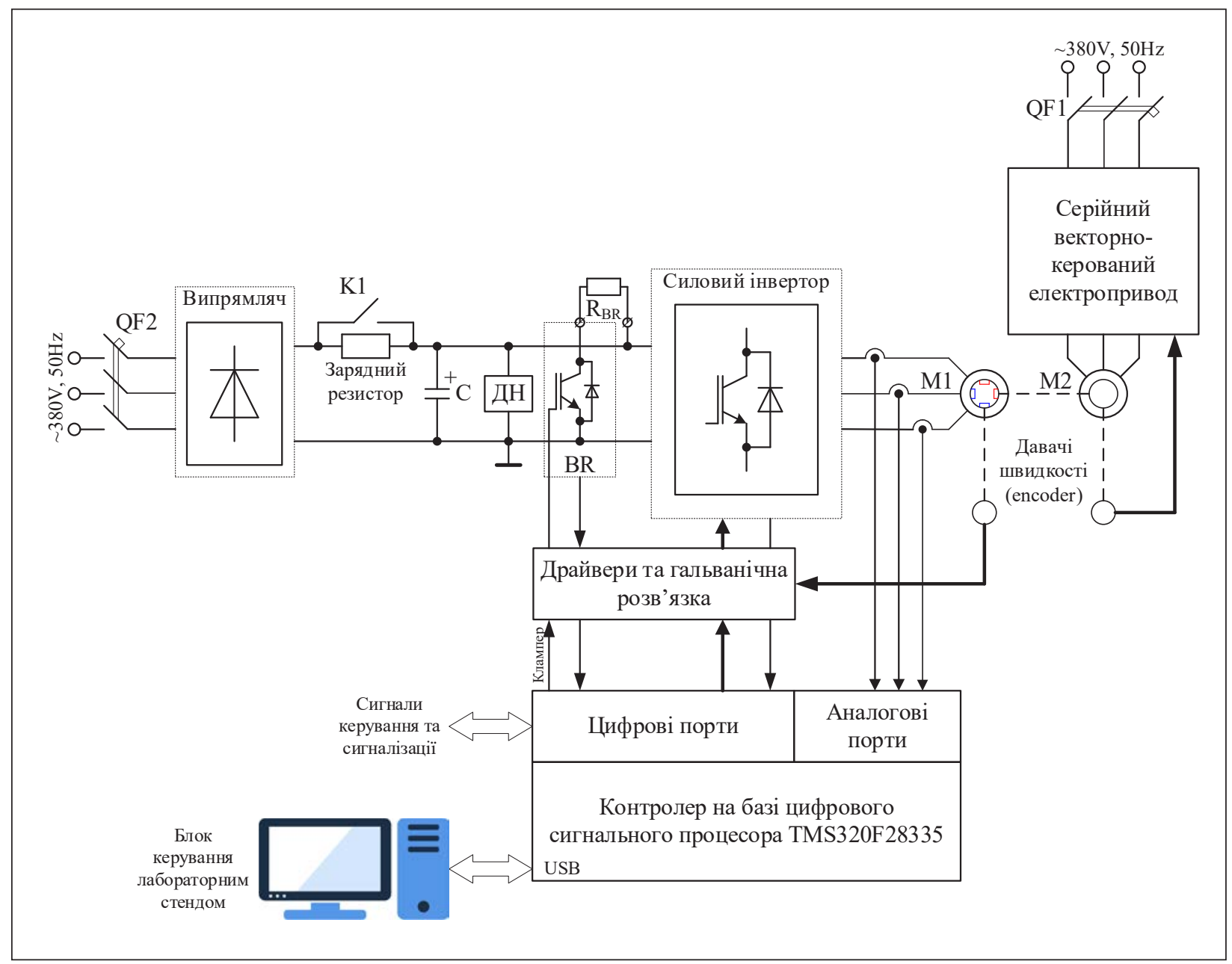

Рис. 1. Функціональна схема експериментальної установки

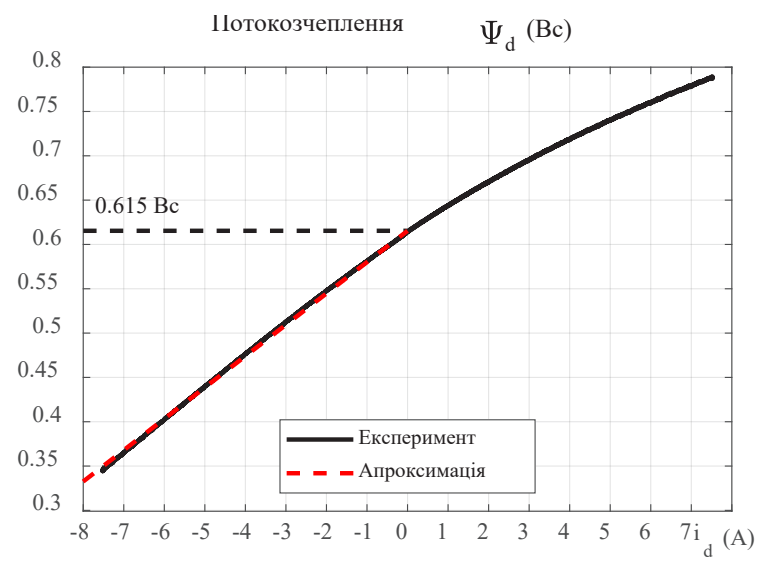

a)

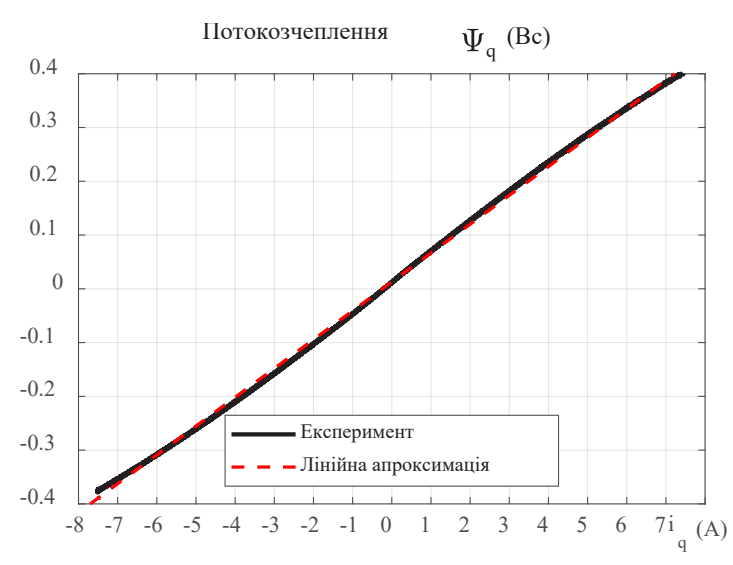

б)

Рис. 2. Залежності потокозчеплень від струму: а) $\Psi_{d}\left(i_{d}\right)$, б) $\Psi_{q}\left(i_{q}\right)$

$$
\Psi_{q}\left(i_{q}\right)=k_{3} i_{q}+k_{4}
$$

де $k_{m}, m=1,2,3,4$ - коефіцієнти апроксимації.

3 рис. $2 \mathrm{a})$ в точці $i_{d}=0$ отримано значення магнітного потоку постійних магнітів $L_{m d} i_{f}=k_{2}=0.615$ Bc. 3 Рис. 2б) при нульовому струмі $i_{q}=0$ пото- козчеплення складає $\Psi_{q}\left(i_{q}=0\right)=k_{4}=0.011 \quad \mathrm{Bc}$ (2\% від $\left.L_{m d} i_{f}\right)$. Отримані значення індуктивностей: $L_{d}=k_{1}=35.4$ мГн за умови $i_{d}<0$, $L_{q}=k_{3}=53.6 \mathrm{м} \Gamma \mathrm{H}$.

Аналогічне дослідження було проведено для випадку ненульового суміжного струму. Залежності 


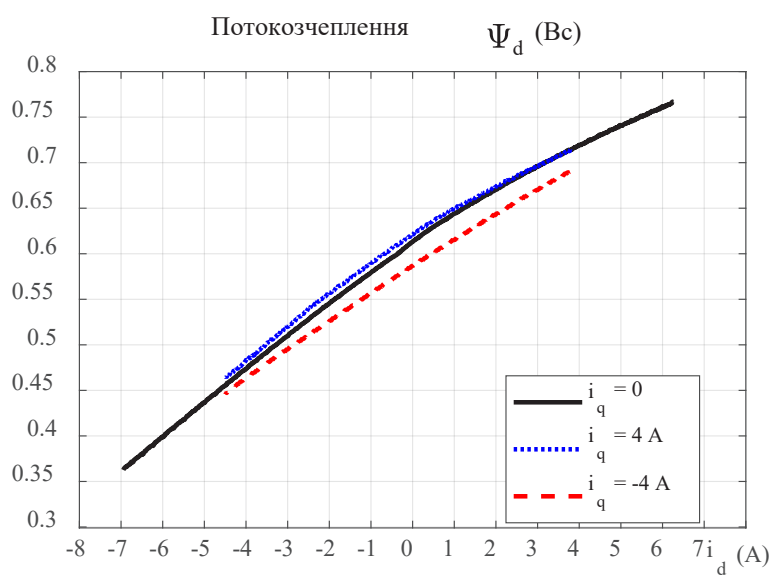

a)

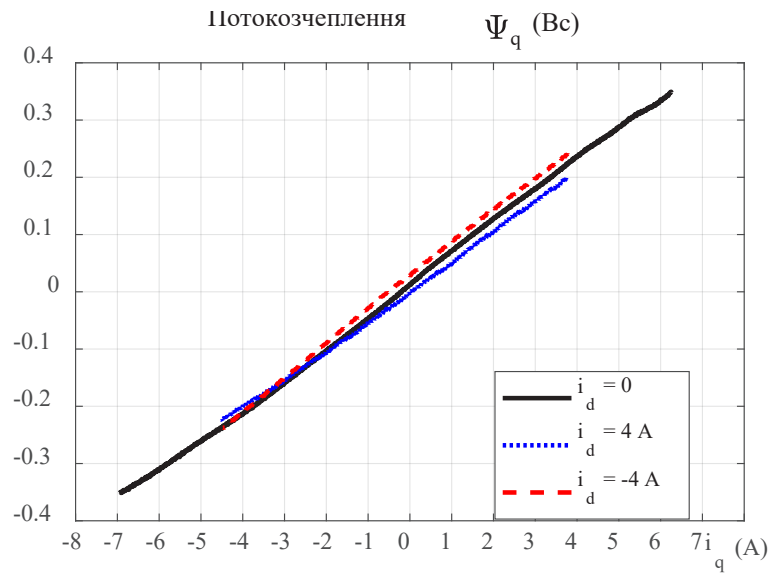

б)

Рис. 3. Залежності потокозчеплень від струму: а) $\Psi_{d}\left(i_{d}, i_{q}\right)$, б) $\Psi_{q}\left(i_{d}, i_{q}\right)$
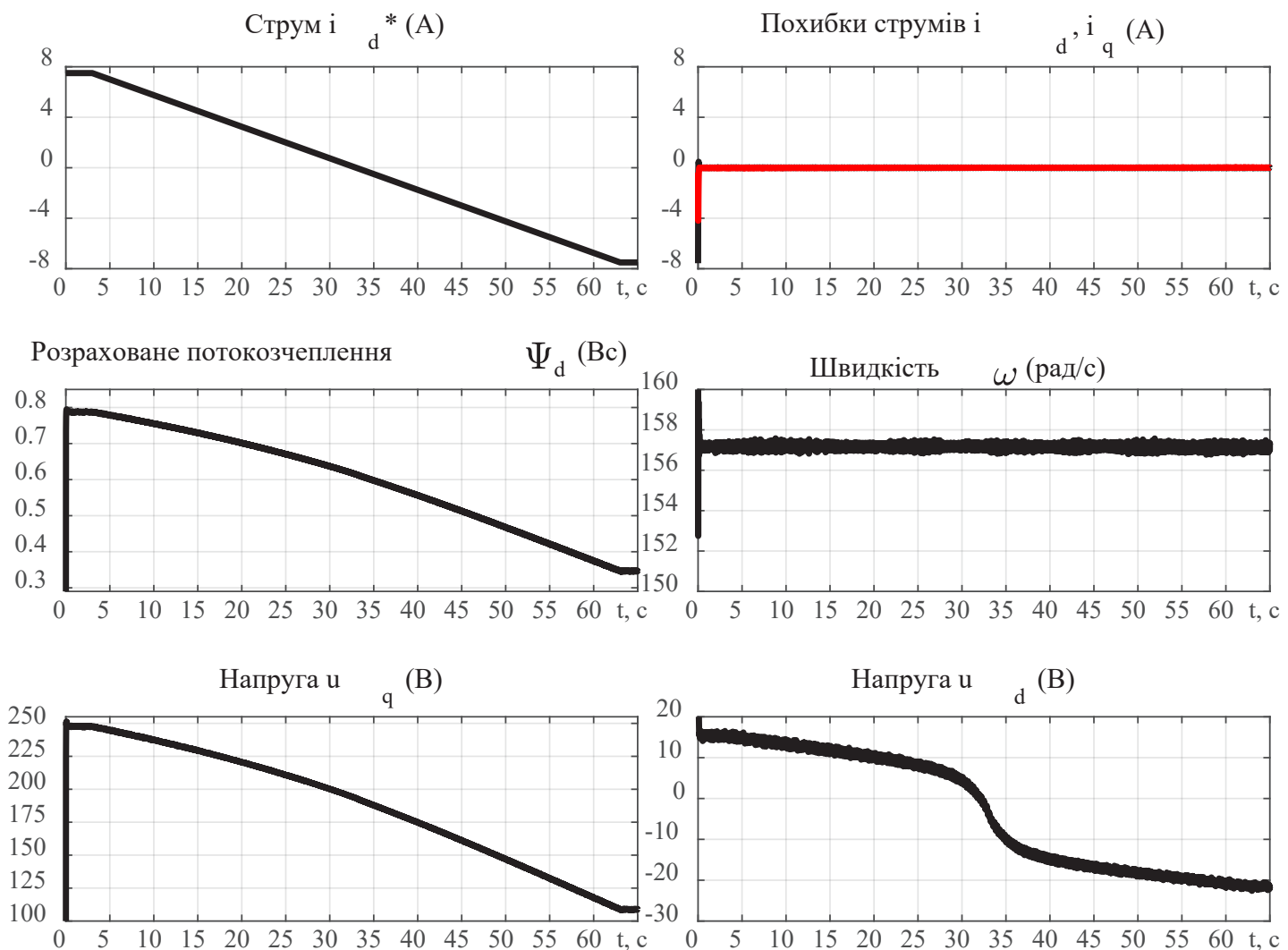

Рис. 4. Експериментальні графіки перехідних процесів дослідження $\Psi_{d}\left(i_{d}\right)$

потокозчеплень , модифікуються з урахуванням падіння напруги на активному опорі статора до такого вигляду:

$$
\Psi_{q}\left(i_{d}, i_{q}\right)=-\frac{u_{d}-R i_{d}}{\omega p_{n}}, \Psi_{d}\left(i_{d}, i_{q}\right)=\frac{u_{q}-R i_{q}}{\omega p_{n}} .
$$

Отримані залежності потокозчеплень зображено на Рис. 3.

Як випливає 3 аналізу Рис. 3 , індуктивність $L_{d}$ (нахил $\Psi_{d}$ ) несуттєво залежить від зміни $i_{q}$. Аналогічний висновок справедливий для $L_{q}$ та $i_{d}$.
Графіки перехідних процесів в умовах тесту ідентифікації $\Psi_{d}\left(i_{d}\right)$ і $\Psi_{q}\left(i_{q}\right)$ (Рис. 2a) та Рис. 2б) представлено на Рис. 4 та Рис. 5 відповідно.

Результати моделювання в системі з ідеальним інвертором (без ШІМ) для випадку дослідження $\Psi_{q}\left(i_{q}\right)$ показано на Рис. 6. Порівнюючи перехідні процеси Рис. 5 і Рис. 6, можна встановити високий ступінь збігу графіків перехідних процесів для змінних, які необхідні для ідентифікації. Водночас суттєва різниця в поведінці напруги $u_{q}$ в реальній установці та в 

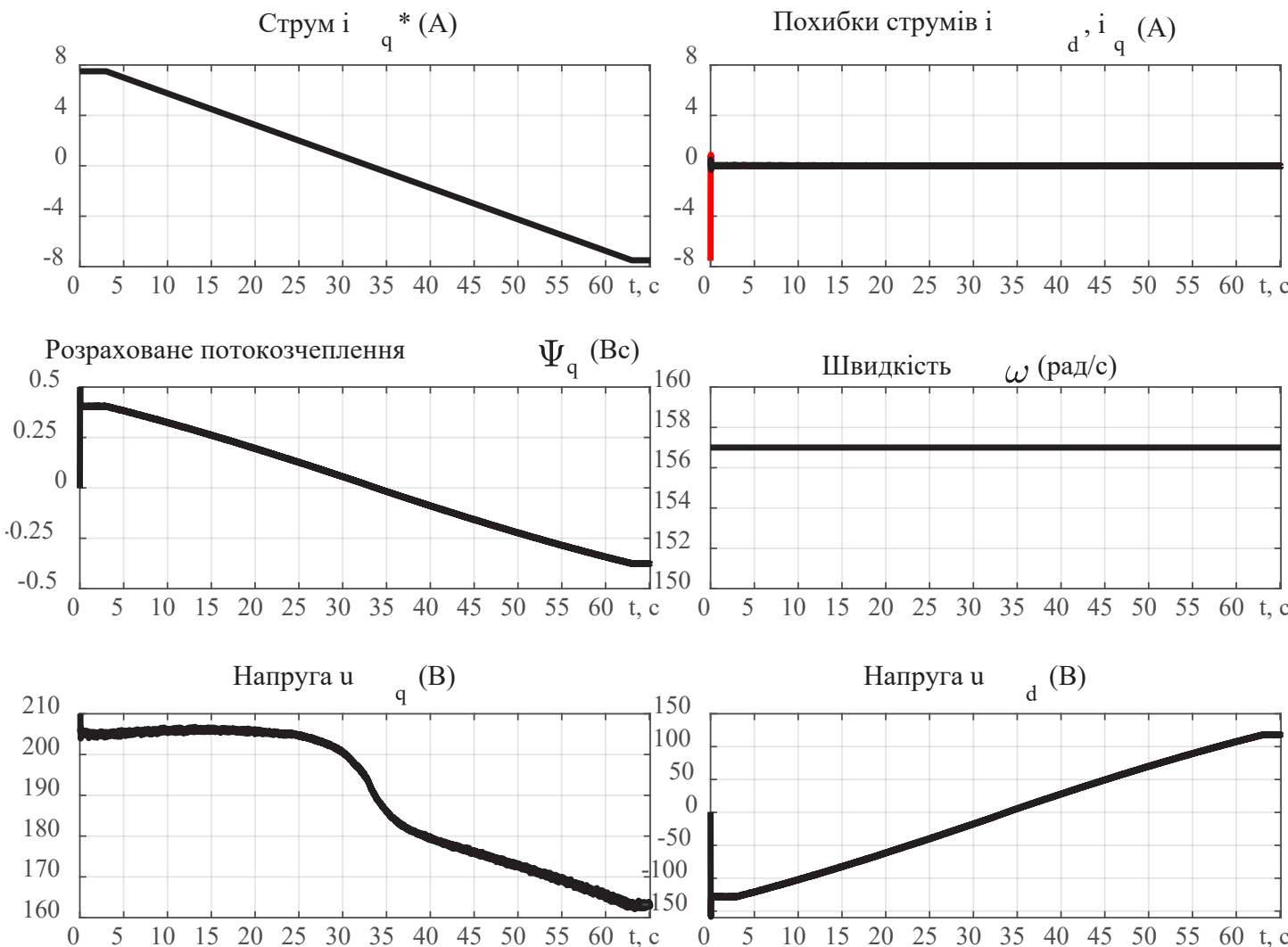

Рис. 5. Експериментальні графіки перехідних процесів дослідження $\Psi_{q}\left(i_{q}\right)$
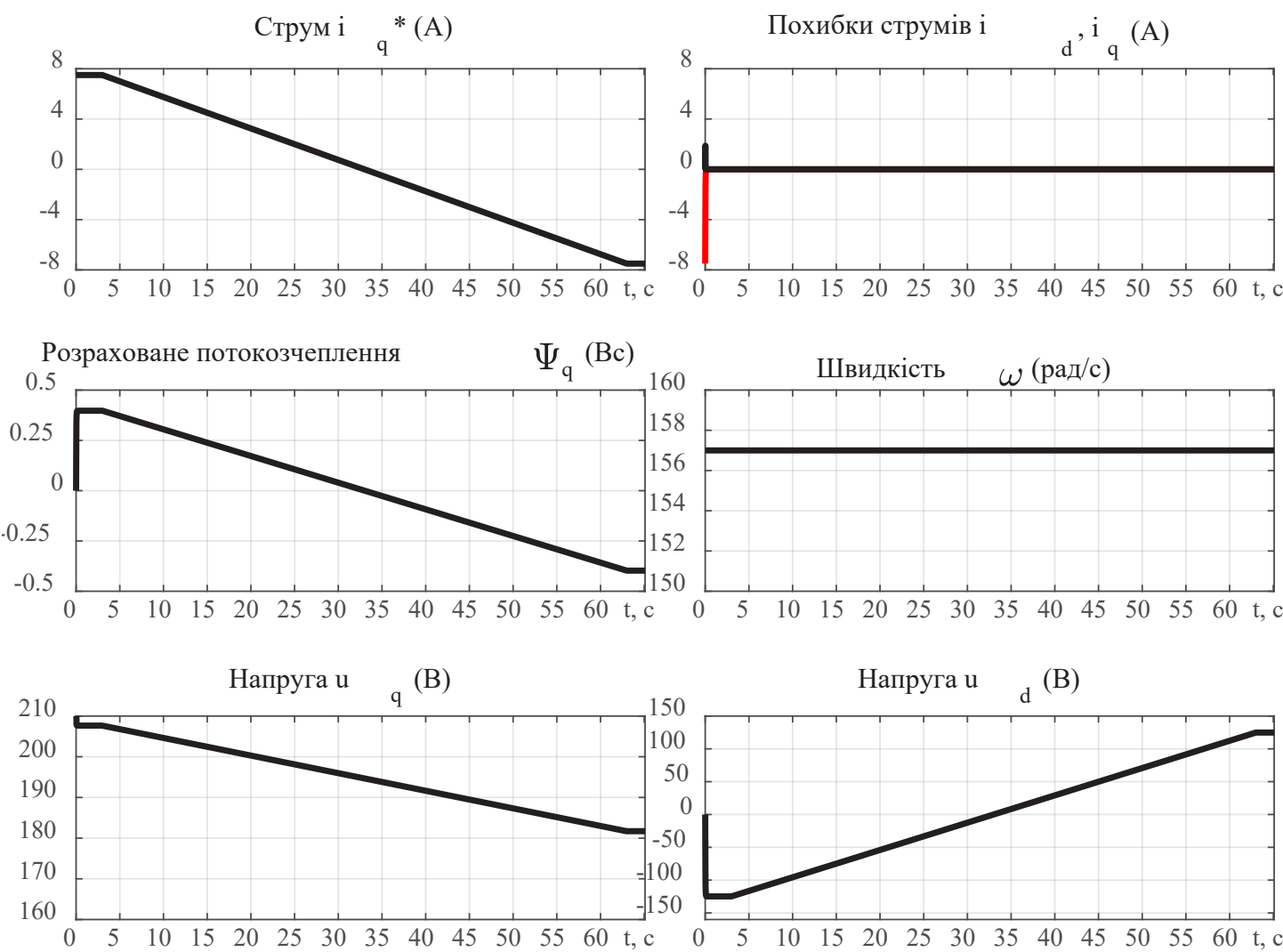

Рис. 6. Результати моделювання в системі з ідеальним інвертором при дослідженні залежності $\Psi_{q}\left(i_{q}\right)$ 
моделюванні свідчить про вплив «мертвого часу» інвертора, що не враховано в моделі, але ця змінна не використовується для визначення залежності $\Psi_{q}\left(i_{q}\right)$. Цей висновок $є$ справедливим також для тесту з визначення залежності $\Psi_{d}\left(i_{d}\right)$.

\section{ВИСНОВКИ}

Запропоновано метод експериментального визначення статичних та інкрементальних індуктивностей, а також магнітного потоку постійних магнітів IPMSM на основі оцінених функцій потокозчеплень від струмів. На точність результатів ідентифікації не впливають неідеальності інвертора і зміни еквівалентного активного опору статора.

Розроблено експериментальну установку 3 IPMSM, яка дозволяє виконувати дослідження про- цесів керування та методів ідентифікації параметрів. 3 використанням розробленої установки експериментально визначено параметри досліджуваного двигуна: магнітний потік постійних магнітів $L_{m d} i_{f}=0.615 \mathrm{Bc}$, індуктивності $L_{d}=35.4$ мГн за умови $i_{d}<0$ та $L_{q}=53.6$ мГн. Показано, що індуктивності машини не залежать від струмів за суміжною віссю.

Додаток. Параметри синхронного двигуна NORD SK 100T/4 TF IG4 (M1): номінальна потужність $P_{n}=3$ кВт, номінальна швидкість $\omega_{n}=220$ рад/с (номінальна частота живлення $f=70$ Гц), номінальний момент $T_{n}=13.6 \mathrm{Hм,} \mathrm{кількість} \mathrm{пар} \mathrm{полюсів} p_{n}=2$, номінальний струм $I_{n}=5.4$ А (діюче значення), активний опір $R_{n}=1.3$ Ом.

\section{REFERENCES}

[1] Sul, S.-K. (2011). Control of electric machine drive systems. John Wiley \& Sons: IEEE Press.

[2] Pellegrino, G., Jahns, T.M., Bianchi, N., Soong, W.L., Cupertino, F. (2016). The rediscovery of synchronous reluctance and ferrite permanent magnet motors: tutorial course notes. New York, NY, USA: Springer.

[3] Wilamowski, B.M., Irwin, J.D. (2017). Power electronics and motor drives. Boca Raton: CRC Press.

[4] Peresada, S., Nikonenko, Y., Reshetnyk, V. (2019). Adaptive speed control and self-commissioning of the surface mounted permanent magnet synchronous motors, IEEE 2nd Ukraine Conference on Electrical and Computer Engineering (UKRCON), Lviv, Ukraine, pp. 388-394.

[5] Amornwongpeeti, S., Kiselychnyk, O., Wang, J., Shatti, N., Shah, N., Soumelidis, M. (2017). Adaptive torque control of IPMSM motor drives for electric vehicles, IEEE 26th International Symposium on Industrial Electronics (ISIE), Edinburgh, pp. 226-231.

[6] Peresada, S., Nikonenko, Y., Reshetnyk, V., Rodkin, D. (2019).Adaptive position control and self-commissioning of the interior permanent magnet synchronous motors,IEEE International Conference on Modern Electrical and Energy Systems (MEES), Kremenchuk, Ukraine, pp. 498-501.

[7] Ren, Y., Liu, G., Chen, Q., Zhou, H. (2016) Online inductance identifications of interior permanent magnet synchronous machine based on adaline neural network, IEEE Vehicle Power and Propulsion Conference (VPPC), Hangzhou, pp. 1-5.

[8] Wang, G., Li, C., Zhang,G., Xu, D. (2017). Self-adaptive stepsize affine projection based parameter estimation of IPMSM using square-wave current injection, CES Transactions on Electrical Machines and Systems, vol. 1, no. 1, pp. $48-57$.

[9] Bobek, V. (2013) PMSM electrical parameters measurement. Application note. Free scale Semiconductor Document Number: AN4680.

[10] Yoon, J.-S, Lee, K.-G, Lee, J.-S, Lee, K.-B. (2015). Off-line parameter identification of permanent magnet synchronous motor using a Goertzel algorithm. Journal of Electrical Engineering and Technology, vol. 10, pp. 2262-2270.

[11] Wu, X., Fu, X., Lin, M., Jia, L. (2019). Offline inductance identification of IPMSM with sequence-pulse injection, IEEE Transactions on Industrial Informatics, vol. 15, no. 11, pp. 6127-6135.

[12] Stumberger, B., Stumberger, G., Dolinar, D., Hamler, A., Trlep, M. (2003). Evaluation of saturation and cross-magnetization effects in interior permanent-magnet synchronous motor, IEEE Transactions on Industry Applications, vol. 39, no. 5, pp. 1264-1271.

[13] Xu, W., Lorenz, R.D. (2014). High-frequency injection-based stator flux linkage and torque estimation for DB-DTFC implementation on IPMSMs considering cross-saturation effects, IEEE Transactions on Industry Applications, vol. 50, no. 6, pp. 3805-3815.

\section{СПИСОК ВИКОРИСТАНОЇ ЛІТЕРАТУРИ}

[1] Sul, S.-K. (2011). Control of electric machine drive systems. John Wiley \& Sons: IEEE Press.

[2] Pellegrino, G., Jahns, T.M., Bianchi, N., Soong, W.L., Cupertino, F. (2016). The rediscovery of synchronous reluctance and ferrite permanent magnet motors: tutorial course notes. New York, NY, USA: Springer.

[3] Wilamowski, B.M., Irwin, J.D. (2017). Power electronics and motor drives. Boca Raton: CRC Press.

[4] Peresada, S., Nikonenko, Y., Reshetnyk, V. (2019). Adaptive speed control and self-commissioning of the surface mounted permanent magnet synchronous motors, IEEE 2nd Ukraine Conference on Electrical and Computer Engineering (UKRCON), Lviv, Ukraine, pp. 388-394.

[5] Amornwongpeeti, S., Kiselychnyk, O., Wang, J., Shatti, N., Shah, N., Soumelidis, M. (2017). Adaptive torque control of IPMSM motor drives for electric vehicles, IEEE 26th International Symposium on Industrial Electronics (ISIE), Edinburgh, pp. 226-231. 


\section{ЕЛЕКТРОЕНЕРГЕТИКА, ЕЛЕКТРОТЕХНІКА ТА ЕЛЕКТРОМЕХАНІКА}

[6] Peresada, S., Nikonenko, Y., Reshetnyk, V., Rodkin, D. (2019). Adaptive position control and self-commissioning of the interior permanent magnet synchronous motors, IEEE International Conference on Modern Electrical and Energy Systems (MEES), Kremenchuk, Ukraine, pp. 498-501.

[7] Ren, Y., Liu, G., Chen, Q., Zhou, H. (2016) Online inductance identifications of interior permanent magnet synchronous machine based on adaline neural network, IEEE Vehicle Power and Propulsion Conference (VPPC), Hangzhou, pp. 1-5.

[8] Wang, G., Li, C., Zhang, G., Xu, D. (2017). Self-adaptive step size affine projection based parameter estimation of IPMSM using square-wave current injection, CES Transactions on Electrical Machines and Systems, vol. 1, no. 1, pp. 48-57.

[9] Bobek, V. (2013) PMSM electrical parameters measurement. Application note. Freescale Semiconductor Document Number: AN4680.

[10] Yoon, J.-S, Lee, K.-G, Lee, J.-S, Lee, K.-B. (2015). Off-line parameter identification of permanent magnet synchronous motor using a Goertzel algorithm. Journal of Electrical Engineering and Technology, vol. 10, pp. 2262-2270.

[11] Wu, X., Fu, X., Lin, M., Jia, L. (2019). Offline inductance identification of IPMSM with sequence-pulse injection, IEEE Transactions on Industrial Informatics, vol. 15, no. 11, pp. 6127-6135.

[12] Stumberger, B., Stumberger, G., Dolinar, D., Hamler, A., Trlep, M. (2003). Evaluation of saturation and cross-magnetization effects in interior permanent-magnet synchronous motor, IEEE Transactions on Industry Applications, vol. 39, no. 5, pp. 1264-1271.

[13] Xu, W., Lorenz, R.D. (2014). High-frequency injection-based stator flux linkage and torque estimation for DB-DTFC implementation on IPMSMs considering cross-saturation effects, IEEE Transactions on Industry Applications, vol. 50, no. 6, pp. 3805-3815. 